\title{
'A more inclusive mind towards the world': English language teaching and study abroad in China from Intercultural citizenship and English as a lingua franca perspectives
}

\author{
Fan (Gabriel) Fang \\ English Language Centre, Shantou University

\section{Will Baker \\ Centre for Global Englishes, University of Southampton}

\begin{abstract}
With the status of English as a global lingua franca (ELF), English is no longer the sole property of its Anglophone native English speakers (NES) problematising the current dominance of Anglophone cultures and NES in the field of English language teaching (ELT). The notion of intercultural citizenship education offers a critical alternative model in language education. To investigate how ELF, intercultural approaches and the concept of intercultural citizenship might be integrated within the field of ELT, a study was conducted in a university located in southeast China. Due to the large number of ELT learners and high degree of student mobility in China these are issue of much relevance in this setting. The research collected qualitative data through face-to-face interviews, email interviews and focus groups with students on study abroad programmes who have both ELT and first hand intercultural experiences. Many students spoke positively about aspects of intercultural citizenship, but classroom instruction offered only limited channels for students to experience and understand intercultural communication and citizenship. In contrast, most of their understanding and experiences were gained outside the classroom during study abroad. Furthermore, many students spoke about the importance of English in their development of intercultural connections and citizenship. We conclude that more in-depth and critical approaches to teaching language, culture and intercultural communication in ELT are needed which foster and cultivate students' sense of intercultural citizenship.
\end{abstract}

\section{Key Words}

English as a Lingua Franca, Intercultural Communication, Intercultural Citizenship, ELT, China

\section{Introduction}

It has been widely recognised that as the English language has spread across the globe, it 
predominantly functions as a lingua franca $(E L F)^{1}$ facilitating communication between people from different lingua-cultural backgrounds. The number of non-native speakers of English (NNSEs) far outnumbers native speakers of English (NSEs). Thus, the position taken in this article is that NSE no longer control, nor should be arbiters, of the language. However, this pluricentric cultural and linguistic landscape is not currently reflected in ELT (English language teaching), where the traditional power relationship that privileges native models of language and Anglophone culture is still largely entrenched.The concept of native speakerism remains the dominant ideology in the field of ELT (Houghton \& Rivers, 2013), while critical perspectives on language and culture instruction and alternative goals and approaches such as intercultural education and citizenship (e.g. Byram, 2008; 2012; Byram et al., 2017) struggle to secure a position. In this paper, we argue that perspectives from ELF and intercultural education and citizenship offer a potentially fruitful, and so far under-explored, combination and alternative to the dominant ideologies of ELT. We relate this discussion to China and issues arising from the increasing role of English in education. This is followed by a presentation of data from a study illustrating core themes in intercultural communication, intercultural citizenship and English language education in China. Finally, implications regarding critical approaches to intercultural communication and citizenship in ELT are discussed.

\section{ELF, intercultural citizenship and ELT}

ELF studies can be seen as adding to post-structuralist perspectives on language and intercultural communication in critically investigating the concepts of language, culture, identity and communication in a manner that emphasises the fluidity of the relationships between them (Baker, 2015; Jenkins, 2015). This questions essentialist correlations between a language, culture, nation and identity. While the nation state still exerts a strong influence on all these areas, it is only one of many scales at which we can view these concepts. ELF studies have illustrated English used to create and negotiate cultural practices, references and identities that move between and across local, national and global scales as well as emergent and hybrid cultural practices and identities created in situ (Kaloscia, 2014; Baker, 2015; Zhu, 2015). Importantly, given the multilingual and multicultural nature of ELF communication (Jenkins, 2015), the boundaries between languages and cultures become blurred. In this sense, ELF communication is transcultural rather than intercultural communication, since it is not

\footnotetext{
${ }^{1}$ In this paper, ELF refers to the 'any use of English among speakers of different first languages for whom English is the communicative medium of choice, and often the only option' (Seidlhofer, 2011: 7).
} 
always clear which culture or language the communication is in-between (see also Kramsch, 2009). Thus, the 'trans' prefix more accurately represents this movement through and across communicative contexts as well as connecting to the similarly dynamic perspectives on language and communication adopted in translanguaging studies (e.g. Canagarajah, 2013; Garcia \& Li, 2014; Li, 2016).

The presence of English in diverse transcultural and translingual settings, with the majority of its users employing it as an additional language, has profound implications for teaching. Firstly, there is no longer a clear target language/target culture correlation. As the use and ownership of English expands beyond the traditional Anglophone countries (typically the US, the UK and Australia in ELT), the relevance of focusing on varieties of English and cultural practices associated with these settings becomes harder to sustain. Secondly, given the diversity of English use the rationale for focusing on any one variety and setting for the language becomes problematic. Instead, if the goal of teaching is to communicate in English, then the focus must be on preparing learners for variety, change and adaptation. Key suggestions have included a focus on the processes of language learning and use (Seidlhofer, 2011) and a 'post-normative' pedagogy (Dewey, 2012, 2015) in which language forms are approached as adaptable and contextually varied rather than as a fixed code. Accompanying this is a wider perspective on the goals of language learning in which the typically narrow communicative competence of ELT, with its emphasis on linguistic competence, is expanded to include pragmatic competence (Jenkins, 2015) and intercultural awareness (Baker, 2015).

In many ways, this links to the arguments made in intercultural approaches to language education more generally (e.g. Byram, 1997, 2008; Kramsch, 2009). Here too, there has been a concern with expanding the notion of communicative competence, especially in the work on intercultural communicative competence (ICC) (Byram, 1997, 2008). Likewise, there has been a reconsideration of the native speaker as a model for language learners and advocating of an intercultural speaker as a more appropriate and attainable alternative with respect to ICC. Although, Byram remains agnostic on the question of linguistic competence in relation to native speakers and 'standard' language in ICC[personal communication and see introduction]. More recently, the discussion has been concerned with the notion of intercultural citizenship as a goal in language education (e.g. Byram, 2008, 2012, 2014; Byram et al., 2017; Lu \& Corbett, 2012; Porto, 2014) and Byram's (2008: 187) definition of 
intercultural citizenship education given below, is well-cited in this literature.

1. Causing/facilitating intercultural citizenship experience, and analysis and reflection on it and on the possibility of further social and/or political activity, i.e. activity that involves working with others to achieve an agreed end;

2. Creating learning/change in the individual: cognitive, attitudinal, behavioural change; change in self-perception; change in relationships with Others (i.e. people of a different social group); change that is based in the particular but is related to the universal.

Intercultural citizenship here combines the international/intercultural and critical from earlier work in foreign language education and intercultural communicative competence with the emphasis on activity in the here and now in citizenship education (Byram et al., 2017: xxiii). Thus, intercultural citizenship involves going beyond learning about 'others' to a kind of learning which results in change in the individual and also produces activity in the community, where that community ranges from the local to the national and, crucially, the international and global.

Intercultural citizenship, as both goal and content for language education, would seem commensurable in many ways with the above discussion of ELF, which also emphasised the importance of identifying with multiple communities in language use that include, but also go beyond, the local and the national. However, to date, there has been little exploration of the cross-over between ELF studies and intercultural citizenship studies, a gap which this paper aims to address. In particular, it is important to recognise that language choices are not marginal issues, and perspectives on the 'appropriate' use of and ownership of English are crucial. Language learners are unlikely to identify with a language in which they feel inferior to an idealised native speaker and that they associate with a 'distant' Anglophone community to which they have little contact. Therefore, how the language being learnt is positioned, and the ideology that underpins this positioning, are central. At present though, approaches that emphasise the use of ELF for intercultural communication and the development of intercultural citizenship clash with the dominant ideology of Anglophone and idealised native speaker models of culture and language in ELT.

\section{ELF, Intercultural Citizenship and student mobility}


An area where many of these issues come to the fore is in student exchanges and mobility both during preparation for the time abroad and the sojourn itself. One of the often stated aims of student mobility is to develop students' intercultural awareness/competence and sense of intercultural/global citizenship (Baker, 2016; Beaven \& Borghetti, 2015; Kinginger, 2013). At the same time, it has long been recognised that study-abroad experiences do not by themselves guarantee growth in intercultural awareness or the development of intercultural citizenship and appropriate support, evaluation and reflection are crucial to successful intercultural student exchanges (Byram \& Feng, 2006; Jackson, 2012). While there is too little space here to deal with all the issues study abroad and student mobility give rise to, two concerns of relevance for this paper are the approach to language and the model of intercultural citizenship.

Firstly, much of the preparation for student mobility has traditionally assumed a correlation between the language of instruction in an institution, a local host community and a national culture and language. However, the increasingly international orientation of many higher education institutions (HEIs) means that such connections can no longer be taken for granted as diverse student and staff bodies make them highly multilingual and multicultural environments. This is particularly the case in Anglophone settings but also in internationally orientated universities that use EMI (English as a medium of instruction), where English most frequently functions as a lingua franca (Jenkins, 2014). Therefore, investigating student sojourners' study-abroad experiences in English using environments and their previous English language education is likely to prove a fruitful area for uncovering possible tensions and discrepancies in approaches to language and intercultural education and the development of intercultural citizenship.

Secondly, while Byram's critical and transformative approach to intercultural citizenship outlined above has received support in language education research (Byram et al., 2017), within education more generally there are a number of competing frameworks. In particular, the neoliberal perspective which emphasises the development of knowledge and skills to enable global mobility for employment and economic benefits has proved pervasive (Aktas et al., 2016). Neoliberal approaches in education, including in language teaching, rather than engaging with communities and social action as envisaged by Byram, may result in increased stratification of social divides to the benefit of cosmopolitan elites (Gray, 2010; Block et. al., 2012). To date, there is insufficient empirical evidence to be able to draw conclusions on how 
educational institutions or individual students view intercultural citizenship. Furthermore, there is likely to be a great deal of variation between the different approaches, suggesting that this is an area of interest for further research.

\section{English and intercultural citizenship in ELT in China}

As already noted, given the large number of English learners and the extent of student mobility in China, particularly to Anglophone countries (Jenkins, 2014), issues around language use, language teaching, study abroad and intercultural citizenship are of great relevance. English has made remarkable gains in status during the last few decades particularly after the 2008 Beijing Olympic Games, 2010 Shanghai Expo and Guangzhou Asian Games and the English teaching industry is booming (Fong, 2009). English is taught from kindergarten, to primary school, to secondary school, and as a compulsory subject in Chinese higher education to both English and non-English majors. It is estimated that there are currently over 400 million English learners in China (Wei \& Su, 2012).

However, this English boom is not without controversy. Although some view the dominance of English as beneficial for generating future economic growth and accelerating China's engagement with the world (e.g. Chang, 2006), others have been more critical. As a country that highly values Confucianism and first language literacy (Deng, 2011, 2014; Fong, 2009), the popularity of English learning in China has generated 'identity anxiety among Chinese involved in learning English' (Gao, 2009: 57-58). Therefore, the notion of zhongxue weiti, xixue weiyong (中学为体, 西学为用: Chinese learning for essence (ti); Western learning for

utility (yong)) is applied in English learning (Gao, 2009; Gil \& Adamson, 2011). This perspective, on the one hand, allows access to the knowledge and opportunities that learning English provides, while on the other hand defends the learning of Chinese for culture and identity (Gil \& Adamson, 2011: 24).

This second view can, however, only be regarded as a temporary solution, and in reality the use and learning of English is far more complex and cannot be explained simply in terms of $t i$ and yong. It is important to realise that learning English in China is not merely a linguistic issue but is embedded in socio-political and ideological grounds between the English language and Chinese culture and identity. Current studies reveal the multiple roles and functions of English in China embracing pride in Chinese culture, but also rebellion against 
authority and increased global connectivity (Li, 2016; Ren et al., 2016). Crucially, research has shown that English is increasingly viewed less as the language of the other and more as part of the multilingual, or translingual resources of its users that 'transforms its users and their subjectivities, creating new spaces for social relations, social structures, and social cognition' ( $\mathrm{Li}, 2016: 21)$. At the same time, the orientation towards a native speaker and Anglophone ideology is still strong, especially in ELT practices (Fang, 2016a, 2016b; Liu, 2016; Wang, 2013). Nonetheless, here too the picture is ambiguous with intercultural communicative competence and global orientations to English forming a core part of the national curriculum in both secondary schools and colleges, but appearing little understood by teachers (Liu, 2016). One of the few empirical studies in China to focus explicitly on intercultural citizenship reported that while university students generally had positive attitudes towards notions associated with intercultural citizenship, their understanding of the concept was still superficial and that more 'systematic' education in intercultural citizenship is needed (Han et al., 2017: 39). Han et al. (2017) conclude that given the relevance and interest in intercultural education and citizenship in China, more research is needed.

\section{Methodology}

To address the gaps identified in the previous literature review in relation to intercultural citizenship education, ELF, ELT and student mobility, we sought to investigate the experiences and attitudes of a group of Chinese learners/users of English who had recently returned from study abroad experiences. Four main research questions guided the analysis and presentation of the data here:

1. What are Chinese university student sojourners' experiences of ELT in relation to intercultural communication, competence and citizenship?

2. What are these students' experiences of intercultural communication in their study-abroad exchange programmes?

3. In what ways, if any, do student sojourners develop awareness of intercultural citizenship as a result of their study-abroad exchange programmes?

4. What is the relationship between students' perceptions and use of English and their perceptions of intercultural communication and intercultural citizenship? 
This research was conducted in a provincial key university located in southeast China. The university has more than 7,000 students, and the English Language Centre, where this study took place, offers language courses to the whole university. As an international university, it provides various exchange programmes for students to study abroad. These exchange programmes aim for student sojourners to develop a sense of intercultural awareness through their experiences.

In terms of participant recruitment, snowball sampling was adopted (Schutt, 2014) through student contacts of the first author, based in China. As the focus is on intercultural citizenship and English in intercultural communication, the researcher recruited student participants who had studied abroad for at least four months as they have more experiences to draw on (see

Table 1).

Table 1. Profiles of Participants

\begin{tabular}{ccccc}
\hline Participants & Gender & Major & Where & Length of Stay \\
Gary & M & English & Ireland & 4 months \\
Laura & F & English & Canada & 4 months \\
Lisa & F & Public Administration & Canada & 4 months \\
Ava & F & English & Ireland & 4 months \\
Hannah & F & English & Ireland & 4 months \\
Lynn & F & Law & Canada & 4 months \\
Andrew & M & Chemistry & New Zealand & 5 months \\
Carter & M & Electronic Information & Canada, Hong Kong & 5 months \\
\hline
\end{tabular}

Data collection involved an initial face to face semi-structured interview covering all four research questions; following this, six participants attended a focus group (Lisa, Hannah, Lynn, Andrew, Carter - and Sally ${ }^{2}$ ) to discuss the themes further. The researcher facilitated the focus group with minimum involvement to ensure that the participants could express their opinions in a relatively relaxing atmosphere. Finally, an email interview was conducted with the eight participants which specifically focused on intercultural/global citizenship ${ }^{3}$ and their

\footnotetext{
${ }^{2}$ Sally participated in the exchange programme to New Zealand for only one month and a half, and thus her interview data is not included.

3 How the terms 'intercultural', 'global' and 'citizenship' are translated is not a trivial matter (Feng, 2006) and we adopted both intercultural citizenship (跨文化公民身份) and global citizenship (全球公民身份) to maximise the changes of participants' familiarity with the terms. Indeed our initial translation of intercultural citizenship yielded little response from the participants whereas a later translation of global citizenship resulted in much more extensive data.
} 
study abroad experiences. All the interviews and the focus group were conducted in Chinese Mandarin.

After data collection, Mandarin transcriptions of the recordings were produced. We adopted content analysis (Schreier, 2012) 'to explore the deeper meanings so as to add interpretive depth and breadth to the analysis' (Jenkins, 2014: 128) and to systematically organise the data. Initial coding based on the research focus and emergent themes was conducted by the first author through listening to the recordings with the transcription. The transcription was then input to NVivo. Next, a second level of coding was undertaken to group the data according to emergent, data-driven themes. After the initial two coding levels, the first author translated the coded data extracts. A final interpretative level of coding, drawing together the previous themes and research questions, was undertaken by both authors, which forms the basis of the themes presented below.

\section{Findings}

The findings from the interviews and focus groups are presented according to the four main themes related to emergent codes and the four research questions (RQ): intercultural citizenship and education (RQ1), intercultural citizenship and study abroad experience (RQ2), intercultural citizenship and learning/change (RQ3), intercultural citizenship and ELF (RQ4).

\section{Intercultural citizenship and education}

For many Chinese university students the only opportunity to gain cultural knowledge and intercultural citizenship experience is through classroom instruction in ELT. However, these student sojourners report a mismatch between their experiences of mainstream methods of ELT and their time abroad. As the examples below show, students felt that:

1. there was insufficient focus on the intercultural dimension in language education,

2. when it was dealt with, it was often at a superficial level

3. the community and activity aspects of intercultural citizenship were missing.

\section{Extract 1}

Hannah: It is not enough. It is possible that I read extensively in my major and delve deeply into some knowledge. [...] However, we need more practical skills to deal with real-life experience abroad. 


\section{Extract 2}

Gary: Most cases have been discussed even when I was in high school [...] They are quite artificial and I do not think I have learned much from the textbooks and classroom instruction.

\section{Extract 3}

Lisa: Chinese students in primary and secondary school are not taught about community service and are not made aware of either intercultural citizenship or community service in nine-year compulsory education.

At the same time, however, all of the participants felt that education could and should form an important part of developing intercultural citizenship, as explained by Laura below.

\section{Extract 4}

Laura: I think this should be one part of the education experience, because with the development of globalization, it's very important to have an international view, whose condition is to have understanding of other countries. Therefore, these kinds of activities are of necessity.

The students suggested a range of ways to do this including 'voluntary activities related to education and environmental protection' (Lynn, Sally); language-related services, such as an English corner (Laura, Hannah); and community activities organised by embassies or experiences of travelling abroad (Gary).

\section{Intercultural citizenship and study abroad experience}

Perhaps unsurprisingly, given the negative perceptions of formal instruction, most of the participants reported developing a greater understanding of intercultural competence/awareness and citizenship though their study abroad experiences. They discussed various intercultural experiences, which raised their levels of intercultural awareness/competence and citizenship as illustrated by Andrew and Sally below.

\section{Extract 5}

Andrew: The most amusing experience is when the host prepared soup for us, and two students and I were sipping the soup with a 'siiiirrr' sound, like when we are eating 
noodle. The host says: 'why are you doing this. This is impolite', and one student responds: 'in my home country, sipping the soup means that it is very delicious'. I also agree with the last comment. The host then replies: 'no. It is not polite to do this here. You need to be quiet when eating'. Interviewer: What happened then?

Andrew: We were then laughing together and let it pass.

\section{Extract 6}

Sally: I do feel the international social environment. More than $70 \%$ students in my postgraduate class are international students, who are from China, India, Canada, and America, etc., and whose backgrounds like age and career are different. Teachers will discuss hot issues like the global environment with us. Besides, the courses are inclusive, because we will discuss the negative news of one country, but we will discuss the facts objectively, instead of attacking others.

Additionally, some of the students actively sought out intercultural citizenship experiences while abroad, undertaking a range of activities in the community.

\section{Extract 7}

Lynn: I once joined the international student organisation and went to local church gatherings to get to know their daily lives.

\section{Extract 8}

Laura: I have attended volunteer work in hospital abroad. I sent the patients in the hospital some candies, cookies with warm smiles with other volunteers on Halloween. Also, I remember one of our volunteers played the piano for them, and we felt glad seeing the smiles on the patients' faces.

However, the responses here were uneven with students revealing different levels of experience and understanding of both intercultural competence/awareness and citizenship. While some participated in numerous activities and reported significant changes, others seemingly only developed a superficial understanding with little meaningful engagement with others as demonstrated with Ava's rather essentialised description below.

\section{Extract 9}


Ava: Paris is not that romantic, and the subway there is dirty and smelly; Santorini is not that beautiful; the thieves in Italy are numerous and rampant; and the students abroad are not that aggressive answering questions in class like the movies show.

Even the same participants reported a range of experiences, for example, Laura who was so positive in extract 8 also felt that the differences in cultures were less than she had expected.

\section{Extract 10}

Laura: Sometimes I was busy with my studies, essays and exams. I did not have time for social activities. At that time, I felt quite depressed, because I felt what I learnt here [in Canada] seemed to have no difference with that at home.

\section{Intercultural citizenship and learning/change}

A crucial part of developing intercultural citizenship is for intercultural experiences to lead to learning and change in the individual and this was part of many participants' experiences of studying abroad. The students reported being more open-minded and interested in engaging with others as well as being more tolerant of difference or 'variety' as Lynn describes in a particularly articulate example below.

\section{Extract 11}

Lynn: I feel that all the changes that have happened to me are positive. First of all study, after a half-year exchange abroad, influenced by the foreign teaching and learning style, I found myself thinking more independently, and having a stronger desire to put forward questions and express my own ideas. What's more, I noticed the significance of equality and inclusiveness in intercultural communication. For instance, there are more chances for me to interact with organizations with different cultural backgrounds and communicate with people from different countries at school. Meanwhile, it will lead to some arguments or even conflicts, however, the key is to communicate equally and understand empathetically. These changes help me and others, because we will have a more inclusive mind towards the world, and also understand and respect variety.

Behavioral changes were also apparent as some students also continued to engage in or expressed a wish to engage in community activities when they returned to China. 


\section{Extract 12}

Laura: After I came back, I have taken part in the visit to the elderly in the community, which are the activities of the College Youth Volunteer Organisation.

\section{Extract 13}

Sally: In the UK, many students will do the voluntary work after class spontaneously, inspired by their own interest and social responsibility, which changes me unconsciously, and makes me willing to be a volunteer.

However, other responses were more ambiguous in the extent to which they showed positive or deep changes in attitudes or behavior in individuals. For example, Ava felt that "white people' (her categorisation) did not understand Chinese people or culture, by saying that in class 'when the teacher talks about Chinese, the white students really cannot understand'. Moreover, participants frequently characterised others by their nationality.

\section{Extract 14}

Gary: I found that European students have a broad understanding of different countries, so they can fit in quickly. Besides, I think it is not only Chinese students who like to stay together, but French and German students also tend to gather together speaking their mother language. However, it is only based on my observation, which could be wrong.

Nonetheless, while such characterisation can lead to essentialism, being open to alternative perspectives is a way of avoiding stereotypes, as Gary appears to recognise in the final comment 'it is only based on my observation, which could be wrong'.

Finally, a number of participants focused on the personal benefits of study abroad and the changes it brought to them fitting in more closely with neoliberal, rather than critical educational, approaches to intercultural citizenship. So for example, Laura stated that 'The overseas experience has broadened my horizon, and meanwhile inspired me to chase the better lifestyle' but at the same time she also reported taking part in more communities activities (see extract 12), suggesting the two perspectives are not necessarily exclusive.

\section{Intercultural citizenship and ELF}


Lastly, language is not a trivial issue in intercultural communication and a number of the students explicitly discussed the relationship between language use and proficiency and their experiences of intercultural communication, as well as linking this to the development of intercultural citizenship. For instance, students in the focus group talked about the importance of being confident when speaking in English in order to develop a sense of ownership or identity through English.

\section{Extract 15}

Carter: I think it is important to be confident when speaking English. I feel that Chinese people dare not speak English and would rather stay with Asian people because they are not confident in English. [...] I think it is important to be confident and learn to integrate with people there.

Lynn: Yes, yes. It is important to learn to be involved in different social settings. I see many university students stay around with other Chinese students.

Andrew: Yes yes many of them.

Carter: Especially those who went abroad in a very young age [...] they have a strong sense of belonging.

For other students, English seemed to be a barrier to intercultural citizenship as for them it was closely associated with Anglophone countries (especially the US) and hence seen a threat to their national identity.

\section{Extract 16}

Lisa: Since we have learned English for nearly 2 decades, we should use this to figure out how others think. But I never talk about this change to my friends even if I consider it important, because I am afraid of being accused of being pro-America.

Indeed, this association between English and Anglophone settings was often repeated, typically as an ideal and hence source of anxiety since as 'non-native' speakers they can never reach this ideal. These mixed attitudes to English and its relationship to identity and development are clearly expressed by Laura who, through the email interview, simultaneously links English to the type of positive personality changes and increased social connections associated with intercultural citizenship, and also to 'shame' in not being 'native 
like'.

\section{Extract 17}

Laura: My personality does change, for I become more optimistic, and willing to talk with others. I feel like that English is very important after the overseas study. [...] My attitude changes. Firstly, I realise its significance, and at the same time, I am very grateful that I have learned this language. Commanding English makes it possible to communicate with people from different places, otherwise, I cannot know a group of good friends.

Extract 18

Laura: I remember that I knew a teaching assistant, who once asked me how long had I learnt English, and I thought about it and found that I had learnt English for 8 years, then he said he would use the standard of 'native speaker' to judge my essay. I thought about it carefully and found out that I still did not have a great progress in English, and I feel ashamed of that.

\section{Discussion and implications}

Despite the increased prominence given to intercultural communication, ELF, globalisation and citizenship in current policy and curricula in Chinese settings, this study, like previous research (e.g. Han et al., 2017; Liu, 2016), found little reference to these concepts in reported ELT practices. This resulted in a mismatch between the participants' experiences of intercultural communication while abroad and what was learnt in the classroom. Nonetheless, regardless of the lack of preparation, the findings here confirm existing research in showing study abroad as a largely positive experience in developing a sense of intercultural competence/awareness and citizenship (e.g. Byram \& Feng, 2006; Byram et al., 2017; Jackson, 2012; Kinginger, 2013; Beaven \& Borghetti, 2015) and all students reported changes in both attitudes and behaviours. However, as might be expected, the extent of changes reported by participants is not even, with some more profound than others, and stereotypes and essentialism still present. It is also not clear from this data to what extent participants developed a sense of cultural identification that went beyond the nation (however complex) and recognised the possibility of hybrid or liminal identifications at a range of 
scales including the local, national and global (Baker, 2015, 2016; Beaven \& Borghetti, 2015). This may in part be due to the majority of experiences taking place in Anglophone settings where the link between a language, culture and nation appeared more straightforward, at least to these students. Nonetheless, as will be discussed in relation to ELF, it remains a concern that the link between English, and Anglophone linguistic and cultural practices often went unchallenged.

Importantly though, the findings clearly show that all participants were able to relate to the concept of intercultural citizenship and felt that it should and could form a valuable part of ELT. While we cannot generalise from this small scale study, another important finding appears to show that neoliberal approach to intercultural citizenship for individual gain (Aktas et al., 2016) and more critical community orientated approach such as those advocated by Byram et al. (2017) are not necessarily mutually exclusive. Some participants described both personal gains and opportunities from study abroad and a sense of intercultural citizenship alongside greater engagement and interest in wider communities.

Another key finding from this study was that many participants recognised, and were able to discuss at length, the importance of language, or specifically English, in intercultural communication and study abroad. English language proficiency, confidence and ownership were all discussed and related to the ability to develop a sense of identity and intercultural citizenship through English. However, like previous research more generally and specifically in China, attitudes were quite mixed (Jenkins, 2007; Fang, 2016a; Ren et al., 2016; Wang, 2013). On the one hand, participants viewed English as the language that connected them to global communities and allowed them to develop a sense of intercultural citizenship. On the other hand, English was still associated with Anglophone settings. This association was seen by some as a threat to national identity, as well as positioning them negatively compared to the idealised Anglophone native speaker of English. As with intercultural competence/awareness and citizenship, it is not clear to what extent participants developed a sense of language in intercultural communication that went beyond the national scale. 
In terms of pedagogic implications, this study joins the growing body of research calling for a more explicit and systematic approach to intercultural education in language teaching (e.g. Baker 2015; Byram, 2008; Kramsch, 2009). The participants in this study appear to have developed their intercultural competence/awareness and sense of intercultural citizenship primarily through their own efforts during study abroad rather than through classroom instruction. This represents both a missed opportunity for a concrete goal in language learning beyond passing exams and also a failure to meet the needs of language learners. Furthermore, there still seems to be a strong attachment to national 'native speaker' conceptions of English in ELT leading to contradictory beliefs about its role as a global language among students. This is particularly concerning given that elements of intercultural competence, citizenship and ELF are present in current Chinese English language policy (Liu, 2016) and underscores the continuing gap between theory, policy and classroom practices.

While there is too little space here to offer detailed recommendations on how this gap might be addressed, it seems clear that both more and a greater variety of cultural content, as well as more intercultural education which focuses on preparation for intercultural communication, is needed. It would also be beneficial to introduce the concept of intercultural citizenship as this provides a framework to help make sense of student experiences of intercultural communication and, we believe, provide an alternative model and aim to the inappropriate native speaker 'standard'. Approaches which take greater account of the intercultural dimension to language education are not new, and there are many models to choose from (Byram, 2008; Byram et al. 2017; Kramsch, 2009). We argue that this needs to be combined with teaching English in a way that recognises its role as a global lingua franca rather than principally as an Anglophone language. While this is a newer area of pedagogic research, studies are beginning to emerge (e.g. Bayyurt and Akcan, 2015) including some that have addressed Asian contexts (Baker, 2015; Galloway, 2013; Kirkpatrick, 2011). Nonetheless, with a few exceptions (Wen, 2015; Han et al., 2017), there has been little discussion directly related to China and even less empirical research and much more is needed. 


\section{Conclusion}

Any conclusions drawn from this research must be tentative since it is a small scale study providing a snap shot in a single site. The findings are also reports of participants' perceptions rather than observations of classroom practices or intercultural interactions. Nonetheless, a number of key themes have emerged that may resonate in other settings. Most importantly, the participants' reports make clear the role experiences of intercultural communication in study abroad have in developing intercultural competence/awareness and a sense of intercultural citizenship. Participants reported changes in behaviour and attitudes leading to a greater understanding of other people and cultures, more openness to diversity and interest in wider communities. However, the depth of these changes appeared quite uneven, and for many, the understanding of 'others' seemed predominantly focused at the national scale in terms of identity, culture and language. A clear mismatch emerged between formal classroom instruction and experiences during study abroad with the majority of students' development of intercultural competence and citizenship taking place in study abroad. There were also mixed understandings and attitudes to ELF, but all participants emphasised the importance of language (English) in experiences of intercultural communication and citizenship. At present, there is little research in China on these topics, and given the increasing role of English in education as well as the large number of Chinese students studying abroad, further research is urgently needed.

\section{Acknowledgements}

This research is supported by the Ministry of Education Project of Key Research Institute of Humanities and Social Sciences at Universities in P. R. China (Project No. 15JJD740007), and Young Creative Talents Project of Social Sciences at Universities in Guangdong Province (Project No. 2015WQNCX034).

We would like to thank all the student participants of this study. We are also grateful to the anonymous reviewers and editors for their comments and feedback on the earlier version of this article. Any lack of clarity and any omissions remain entirely our responsibility. 


\section{References}

Aktas, F., Pitts, K., Richards, J. C., \& Silova, I. (2016). Institutionalizing Global Citizenship: A Critical Analysis of Higher Education Programs and Curricula. Journal of Studies in International Education, 1-16.

Baker, W. (2015). Culture and identity through English as a lingua franca: rethinking concepts and goals in intercultural communication Berlin: De Gruyter Mouton.

Baker, W. (2016). English as an academic lingua franca and intercultural awareness: student mobility in the transcultural university. Language and Intercultural Communication.

Bayyurt, Y., \& Akcan, S. (Eds.). (2015). Current perspectives on pedagogy for ELF. Berlin: De Gruyter Mouton.

Beaven, A., \& Borghetti, C. (2015). Editorial: Intercultural education for student mobility. Intercultural Education, 26(1), 1-5.

Block, D., Gray, J., \& Holborow, M. (Eds.). (2012). Neoliberalism and Applied Linguistics. Abingdon: Routledge.

Byram, M. (1997). Teaching and assessing intercultural communicative competence. Clevedon: Multilingual Matters.

Byram, M. (2008). From foreign language education to education for intercultural citizenship: essays and reflections. Clevedon: Multilingual Matters Ltd.

Byram, M. (2012). Conceptualizing intercultural (communicative) competence and intercultural citizenship. In J. Jackson (Ed.), The Routledge handbook of language and intercultural communication (pp. 85-97). London: Routledge.

Byram, M. (2014). Twenty-five years on - from cultural studies to intercultural citizenship. Language, Culture and Curriculum, 27(3), 209-225.

Byram, M., \& Feng, A. (Eds.). (2006). Living and studying abroad. Clevedon: Multilingual Matters.

Byram, M., Golubeva, I., Han, H., \& Wagner, M. (Eds.). (2017). From Principles to Practice in Education for Intercultural Citizenship. Bristol: Multilingual Matters.

Canagarajah, S. (2013). Translingual practice: Global Englishes and cosmopolitan relations. London: Routledge.

Chang, J. (2006). Globalization and English in Chinese higher education. World Englishes, 25(3/4), 513-525.

Deng, Z. (2011). Confucianism, modernization and Chinese pedagogy: An introduction, Journal of Curriculum Studies, 43(5), 561-568.

Deng, Z. (2014). Confucianism, modernization and Chinese pedagogy (Part Two): Continuing the conversation. Journal of Curriculum Studies, 46(3), 301-304.

Dewey, M. (2012). Towards a post-normative approach: learning the pedagogy of ELF. Journal of English as a Lingua Franca, 1(1), 141-170.

Dewey, M. (2015). Time to wake up some dogs! Shifting the culture of language in ELT. In Y. Bayyurt \& S. Akcan (Eds.), Current Perspectives on Pedagogy for ELF (pp. 121-134). Berlin: De Gruyter Mouton.

Fang, F. (2016a). Investigating attitudes towards English accents from an ELF framework. The Asian Journal of Applied Linguistics, 3(1): 68-80.

Fang, F. (2016b). 'Mind your local accent': Does accent training resonate to college students' English use?. Englishes in Practice, 3(1): 1-28. 
Feng, A. (2006). Contested notions of citizenship and citizenship education - The Chinese case. In G. Alred, M. Byram \& M. Fleming (Eds.), Education for intercultural citizenship: concepts and comparisons (pp. 86-105). Clevedon: Multilingual Matters.

Fong, E.T.Y. (2009). English in China: some thoughts after the Beijing Olympics. English Today, 25(1), 44-49.

Galloway, N. (2013). Global Englishes and English Language Teaching (ELT) - Bridging the gap between theory and practice in a Japanese context. System, 41(3), 786-803.

Gao, Y. (2009). Sociocultural contexts and English in China: retaining and reforming the cultural habitus. In: J. Lo Bianco, J. Orton, \& Gao Y., (eds.). China and English: Globalisation and the Dilemmas of Identity (pp. 56-78). Bristol: Multilingual Matters.

García, O., \& Li, W. (2014). Translanguaging: Language, Bilingualism and Education. . Basingstoke: Palgrave Macmillan.

Gil, J., \& Adamson, B. (2011). The English language in Mainland China: a sociolinguistic profile. In A. Feng, (Ed.), English language education across greater China (pp. 23-45). Bristol: Multilingual Matters.

Gray, J. (2010). The Construction of English: Culture, Consumerism and Promotion in the ELT Global Coursebook. Basingstoke: Palgrave Macmillan

Han, H., Li, S., Hongtao, J., \& Yuqin, Z. (2017). Exploring perceptions of Intercultural Citizenship among English Learners in Chinese Universities. In M. Byram, I. Golubeva, H. Han \& M. Wagner (Eds.), From Principles to Practice in Education for Intercultural Citizenship (pp. 25-44). Bristol: Multilingual Matters.

Houghton, S.A., \& Rivers, D.J. (Eds). (2013). Native-speakerism in Japan: Intergroup dynamics in foreign language education. Bristol: Multilingual Matters.

Jackson, J. (2012). Education abroad. In J. Jackson (Ed.), The Routledge handbook of language and intercultural communication (pp. 449-463). London: Routledge.

Jenkins, J. (2007). English as a Lingua Franca: attitude and identity. Oxford: Oxford University Press.

Jenkins, J. (2014). English as a Lingua Franca in the International University. The politics of academic English language policy. London: Routledge.

Jenkins, J. (2015). Repositioning English and multilingualism in English as a Lingua Franca. Englishes in Practice, 2(3), 49-85.

Kaloscia, K. (2014). Communities of practice and English as a lingua franca: A study of Erasmus students in a Central-European context. Berlin: DeGruyter Mouton.

Kinginger, C. (Ed.). (2013). Social and cultural aspects of language learning in study abroad. Amsterdam: John Benjamins.

Kirkpatrick, A. (2011). English as an Asian lingua franca and the multilingualmodel of ELT. Language Teaching, 44(2), 212 - 224.

Kramsch, C. (2009). The multilingual subject. Oxford: Oxford University Press.

Li, W. (2016). New Chinglish and the Post-Multilingualism challenge: Translanguaging ELF in China. Journal of English as a Lingua Franca, 5(1), 1-25.

Liu, H. (2016). Language policy and practice in a Chinese junior high school from global Englishes perspective. PhD, University of Southampton.

Lu, P., \& Corbett, J. (2012). An intercultural approach to second language education and citizenship. In J. Jackson (Ed.), The Routledge handbook of language and intercultural 
communication (pp. 325-329). London: Routledge.

Porto, M. (2014). Intercultural citizenship education in an EFL online project in Argentina. Language and Intercultural Communication, 14(2), 245-261.

Ren, W., Chen, Y. \& Lin, C. (2016). University students' perceptions of ELF in mainland China and Taiwan. System, 56, 13-27.

Schreier, M. (2012). Qualitative content analysis in practice. London: Sage.

Schutt, R.K. (2014). Investigating the social world: The process and practice of research, (8th edn). Thousand Oaks: Sage.

Seidlhofer, B. (2011). Understanding English as a Lingua Franca. Oxford: Oxford University Press.

Wang, Y. (2013). Non-conformity to ENL norms: a perspective from Chinese English users. Journal of English as a Lingua Franca, 2(2), 255 - 282.

Wen, Q. (2015). Teaching culture(s) in English as a lingua franca in Asia: dilemma and solution. Journal of English as a Lingua Franca, 5(1), 155-177.

Wei, R., \& Su, J. (2012). The statistics of English in China. English Today, 28(3), 10-14.

Zhu, H. (2015). Negotiation as the Rule of Engagement in Intercultural and Lingua Franca Communication: Meaning, Frame of References and Interculturality. Journal of English as a Lingua Franca, 4(1), 63-90. 